\title{
Patterns of Circulating Corticosterone in a Population of Rattlesnakes Afflicted with Snake Fungal Disease: Stress Hormones as a Potential Mediator of Seasonal Cycles in Disease Severity and Outcomes
}

\author{
Craig Lind ${ }^{1,2, *}$ \\ Ignacio T. Moore ${ }^{3}$ \\ Çağlar Akçay ${ }^{3}$ \\ Ben J. Vernasco ${ }^{3}$ \\ Jeffrey M. Lorch ${ }^{4}$ \\ Terence M. Farrell ${ }^{1}$ \\ ${ }^{1}$ Department of Biology, Stetson University, Deland, Florida \\ 32723; ${ }^{2}$ Department of Natural Sciences and Mathematics, \\ Stockton University, Galloway, New Jersey 08201; \\ ${ }^{3}$ Department of Biological Sciences, Virginia Tech, Blacksburg, \\ Virginia 24061; ${ }^{4}$ US Geological Survey, National Wildlife \\ Health Center, Madison, Wisconsin 53711
}

Accepted 10/31/2017; Electronically Published 12/29/2017

\begin{abstract}
Snake fungal disease (SFD) is an emerging threat to snake populations in the United States. Fungal pathogens are often associated with a physiological stress response mediated by the hypothalamopituitary-adrenal axis (HPA), and afflicted individuals may incur steep coping costs. The severity of SFD can vary seasonally; however, little is known regarding (1) how SFD infection relates to HPA activity and (2) how seasonal shifts in environment, life history, or HPA activity may interact to drive seasonal patterns of infection severity and outcomes. To test the hypothesis that SFD is associated with increased HPA activity and to identify potential environmental or physiological drivers of seasonal infection, we monitored baseline corticosterone, SFD infection severity, foraging success, body condition, and reproductive status in a field-active population of pigmy rattlesnakes. Both plasma corticosterone and the severity of clinical signs of SFD peaked in the winter. Corticosterone levels were also elevated in the fall before the seasonal rise in SFD severity. Severely symptomatic snakes were in low body condition and had elevated corticosterone levels compared to moderately infected and uninfected snakes. The monthly mean severity of SFD in the population was negatively related to populationwide estimates of body condition and temperature measured in the precedent month and positively correlated with corticosterone levels measured in the precedent month. Symptomatic females
\end{abstract}

${ }^{*}$ Corresponding author; e-mail: craig.lind@stockton.edu.

Physiological and Biochemical Zoology 91(2):765-775. 2018. (C) 2017 by The University of Chicago. All rights reserved. 1522-2152/2018/9102-17071\$15.00. DOI: $10.1086 / 695747$ were less likely to enter reproductive bouts compared to asymptomatic females. We propose the hypothesis that the seasonal interplay among environment, host energetics, and HPA activity initiates trade-offs in the fall that drive the increase in SFD prevalence, symptom severity, and decline in condition observed in the population through winter.

Keywords: glucocorticoid, hypothalamo-pituitary-adrenal axis, allostatic load, conservation physiology, Ophidiomyces ophiodiicola, cort-fitness hypothesis.

\section{Introduction}

In vertebrate populations, opportunistic or emergent diseases can induce stress in individuals (Korte et al. 2005; Gabor et al. 2013). The stress response, defined here as a behavioral or physiological activity initiated to cope with an aversive stimulus (Martin 2009), can be mediated by the hypothalamo-pituitary-adrenal axis (HPA) and its downstream products, adrenal glucocorticoids (GCs). GCs act to mobilize energy and influence the allocation of resources among competing life-history functions such as energy storage, growth, metabolism, reproduction, and immune function (Moore and Zoeller 1985; Buttemer et al. 1991; Morici et al. 1997; Berger et al. 2005). The activity of the HPA and allocation strategies may shift in response to seasonal fluctuations in the resource or biophysical environment or in association with the energetic demands of seasonal reproduction (Romero 2002, 2004; Moore and Jessop 2003; Reeder and Kramer 2005). Seasonal fluctuation in HPA activity and the HPA response to disease may therefore alter host condition, immunocompetence, or both (Simmaco et al. 1997; Marin et al. 2007; Thomas and Woodley 2015) and may play a role in driving seasonal patterns and outcomes of infection.

The cort-fitness hypothesis posits that the magnitude of a challenge to homeostasis (stressor) is positively related to circulating GC levels and negatively related to fitness (Bonier et al. 2009b). In response to a stressor, adrenal GC production mobilizes energy to pay the energetic cost of behavioral or physiological coping mechanisms (allostatic load), and when allostatic load (Sapolsky et al. 2000; McEwen and Wingfield 2003) exceeds the ability to compensate through feeding, individuals enter negative energy balance and may be forced to make energetic trade-offs that result in decreased fitness, that is, allostatic overload (Wingfield et al. 1998). The cort-fitness hypothesis does not hold across all physiological and ecological contexts (Bonier et al. 2009a). However, 
wildlife diseases represent an acute (or potentially chronic) environmental stressor that can activate the HPA response and impose an allostatic load on hosts (Romero 2002; Korte et al. 2005). Even in instances where physiological consequences of the HPA response are initially due to other stressors that predispose an individual to infection, the resulting disease state may further exacerbate the response. In the context of disease, it is therefore likely that the tenants of the cort-fitness hypothesis hold, and one would predict that circulating GCs are higher in more severely infected individuals and severe infection is related to reduced fitness. The fitness costs of allostatic overload result from the combination of both the allostatic load and the ability to pay coping costs through foraging. Therefore, understanding seasonal relationships among HPA function, foraging success, population energetic status, and disease state is an important step toward a mechanistic explanation of seasonal patterns of infection severity and outcomes in terms of fitness.

Recently, symptoms of a fungal disease have become increasingly prevalent in snake populations in the United States (Latney and Wellehan 2013; Dolinski et al. 2014; Sutherland et al. 2014; McBride et al. 2015; Lorch et al. 2016). The causative agent of the disease (from here on, snake fungal disease [SFD]) is the fungus Ophidiomyces ophiodiicola (Lorch et al. 2015), and population declines and local extirpation have been attributed to its emergence in several snake populations (Allender et al.2011; Clark et al. 2011). It is unclear at this point whether SFD is best described as a newly introduced wildlife disease or whether shifts in environmental conditions have rendered hosts more susceptible to infection (Lorch et al. 2016). Infection rates based on clinical signs of SFD vary both by year (Cheatwood et al. 2003) and seasonally (McCoy et al. 2017) in one snake population and have been anecdotally linked to periods of winter hibernation in others (Lorch et al. 2016). A recent study conducted in pigmy rattlesnakes Sistrurus miliarius in central Florida (McCoy et al. 2017) described three correlates of the severity of clinical signs of SFD: (1) severity correlates negatively with individual body condition, (2) severity within the population rises in months following a seasonal decline in surface air temperature and a measure of innate immune function, and (3) costly life-history functions (i.e., pregnancy and vitellogenesis) were not associated with impaired immune function, and reproductive female snakes displayed fewer clinical signs of SFD compared to the general population. Little is known regarding whether HPA activity is associated with the relationships among environment, physiology, and SFD infection severity described in McCoy et al. (2017) or in any other snake population.

To address the gap in our understanding of the physiological state of individuals with SFD, how HPA activity relates to seasonal patterns of infection, and how the interplay among these variables might affect the consequences of infection in terms of fitness, we quantified corticosterone (cort; the primary GC in reptiles) levels, body condition, reproductive condition, and the severity of clinical signs of SFD in a population of pigmy rattlesnakes over the course of $18 \mathrm{mo}$. We aimed to test the broad hypothesis that infected snakes experience physiological stress and increased allostatic load and that seasonal shifts in HPA function are related to observed seasonal patterns of disease by asking four main ques- tions: (1) Do seasonal patterns in baseline cort concentrations follow seasonal patterns in SFD symptom severity? (2) Is infection severity related to circulating cort levels? (3) Is HPA function related to energetic status in infected and uninfected snakes? (4) Does infection severity correlate with the decision to enter seasonal reproductive bouts in females?

\section{Methods}

\section{Field Sampling}

From January 18, 2015, to July 27, 2016, blood was sampled, reproductive condition was determined, and mass and length were recorded in free-ranging adult pigmy rattlesnakes at Lake Woodruff National Wildlife Refuge in central Florida $\left(29^{\circ} 05^{\prime} \mathrm{N}, 81^{\circ} 26^{\prime} \mathrm{W}\right)$. Surface-active snakes were located visually. A total of 459 blood samples were taken from 224 individual snakes. Snout-to-vent length (SVL) was measured using a squeeze box, and individuals were weighed using a Pesola spring scale. Each snake was marked by intraperitoneal injection of a passive integrated transponder tag (Avid, Norco, CA), a marking technique that does not appear to cause negative impacts in this species (Jemison et al. 2005). A blood sample was drawn from the caudal vein using a 1-mL syringe and a 27-gauge needle within 5 min of initial contact to minimize any effect that capture might have on cort values (Schuett et al. 2004). Each sample was placed in a $1.5-\mathrm{mL}$ microcentrifuge tube containing two drops of ethylenediaminetetraacetic acid and placed on ice for transport back to the lab within $4 \mathrm{~h}$. Samples were centrifuged at 13,000 rpm for $10 \mathrm{~min}$ to separate the red blood cells from plasma. Plasma samples were stored at $-80^{\circ} \mathrm{C}$ and shipped overnight on dry ice to Virginia Tech for radioimmunoassay.

Snake measurements and disease severity scores that were used as part of a previous study are presented (McCoy et al. 2017). To determine whether the visual diagnosis and scoring of lesions employed in McCoy et al. (2017) corresponded to the presence or relative abundance of Ophidiomyces ophiodiicola, sterile swabs (Medical Wire product MW113, Corsham, UK) were used to sample the skin of 29 snakes between October 1 and December 11, 2016. The front half of each snake was secured in a sterilized plastic tube. Swabs were wetted with $20 \mu \mathrm{L}$ of sterile deionized water and run five times up and down both the dorsal and ventral surfaces of the posterior half of each snake. If lesions were visible, swabs were intentionally run over the lesions. Swabs were placed in sterile $1.5-\mathrm{mL}$ microcentrifuge tubes and stored on ice until returning to the lab, at which point tubes were stored at $-80^{\circ} \mathrm{C}$ until shipment on dry ice to the US Geological Survey-National Wildlife Health Center (Madison, WI) for real-time polymerase chain reaction (PCR) analysis for O. ophiodiicola DNA. Tongs and tubes used to restrain snakes were sterilized between each sample by soaking for $30 \mathrm{~s}$ in a $10 \%$ bleach solution followed by a 30 -s rinse in water.

Monthly mean, minimum, and maximum temperatures were compiled from data recorded at a local weather station and available online at MesoWest $\left(29^{\circ} 10^{\prime} \mathrm{N}, 81^{\circ} 37^{\prime} \mathrm{W}\right.$; station no. LWQF1). The severity of SFD clinical signs was scored on a 0-3-point scale (see McCoy et al. 2017). The scale was set at the start of the experiment, and all SFD scores were assigned by a single observer. A body condition index (BCI) was calculated for each snake by 
taking the residual of a linear regression of log-transformed mass on log-transformed SVL. Females were manually palpated in the field to identify the presence of follicles and embryos (Taylor and DeNardo 2005). Seasonal estimates of foraging success were taken from historical data recorded from the Lake Woodruff population (May and Farrell 2012), where foraging success was estimated by the proportion of individuals captured each month with a diagnosable prey bolus (percent with bolus).

\section{Radioimmunoassay}

Plasma cort levels were determined via radioimmunoassay of plasma in two separate assays as described in Lind et al. (2010). Samples were extracted in dichloromethane, then dried in a $40^{\circ} \mathrm{C}$ water bath under nitrogen gas. Samples were incubated overnight in $100 \mu \mathrm{L}$ of antiserum (Esoterix Endocrinology, Calabasas Hills, CA) and $100 \mu \mathrm{L}$ of tritiated steroid. Unbound steroid was separated from bound steroid using dextran-coated charcoal. A liquid scintillation counter was used to count bound steroid in samples, and final concentrations were corrected for extraction efficiency. Mean recovery for cort was $\sim 65 \%$. Serial dilutions for the standard curves were performed in duplicate (curve range $=4-2,000 \mathrm{pg}$ ). The limit of detection was $3.5 \mathrm{ng} / \mathrm{mL}$, and the intra-assay and interassay coefficients of variation were $12.5 \%$ and $11.9 \%$, respectively.

\section{Real-Time PCR}

To validate our SFD scoring system, we swabbed a subset of snakes and tested them for O. ophiodiicola by real-time PCR. We hypothesized that the amount of the pathogenic fungus detected by PCR would correlate with the disease severity score based on clinical signs. DNA was extracted from swabs with PrepMan Ultra Sample Preparation Reagent (Applied Biosystems, Foster City, CA) and zirconium/silica beads (Hyatt et al. 2007). Five microliters of extracted DNA was then used as template for real-time O. ophiodiicola-specific PCR targeting the internal transcribed spacer region (Bohuski et al. 2015). All samples were run on a single PCR plate with a negative PCR control (no template added) and a negative extraction control (extraction procedure performed on a sterile swab). A standard curve was also run on the plate using various concentrations of target amplicon cloned into a plasmid. The estimated number of copies of PCR target in the reactions used to generate the standard curve was a series of $10 \mathrm{di}$ lutions ranging from $1.16 \times 10^{2}$ to $1.16 \times 10^{6}$. Samples were considered to be positive for O. ophiodiicola if they crossed the threshold at or below 40 replication cycles (Bohuski et al. 2015).

\section{Statistical Analyses}

The effects of season (month), infection status (none $=0-0.5$, moderate $=1-1.5$, and severe $=2-3$; see McCoy et al. 2017), reproductive status (nonreproductive, pregnant, and vitellogenic), and body condition on ln-transformed cort levels were analyzed using repeated-measures models using SAS PROC MIXED. Cort values were $\ln$ transformed in all analyses to satisfy the normality assumption of parametric statistics. Each snake was assigned to one of three reproductive categories based on manual palpation. Nonreproductive individuals were those that were not pregnant or vitellogenic at the time of sampling. Because no sex effects were evident and the study concerned the physiological response to SFD in general, males and females were included in a single model. The effect of reproductive status on cort was analyzed in a model including month to account for seasonal variation resultant from factors other than reproduction. To examine the effects of month, body condition (BCI), and clinical sign severity, a model including all three terms and all second-order interactions (full model) was used. An autoregressive covariance structure was chosen based on Akaike information criterion scores (Burnham and Anderson 2002). Additionally, monthly patterns in cort were analyzed in the absence of covariates in a repeated-measures model including the effect of month only. Monthly patterns of cort in snakes with severe clinical signs and with no clinical signs were also analyzed separately using by single-factor ANOVA. This analysis violated the assumption of independence but provided a more interpretable visualization of the infection status $\times$ month interaction term in the full model. Seasonal patterns in BCI and SFD score over the course of the study were analyzed using a repeated-measures model in PROC MIXED. On a few occasions, snakes were sampled twice in the same month. If snakes were sampled twice within the same month, the second sample was discarded from the analysis. Meteorological seasons (December-February $=$ winter; MarchMay $=$ spring; June-August $=$ summer; September-November $=$ fall) were used in the discussion of seasonal patterns.

To examine seasonal correlates of the severity of clinical signs of SFD in the population, JMP, version 11 (SAS Institute, Cary, NC), was used to run Pearson correlations (with a Bonferroniadjusted $\alpha$ of 0.005 ) between mean monthly SFD score and four variables calculated in the preceding month: percent with bolus, mean baseline cort, mean BCI, and mean surface air temperature for each month (11 from 2015 and 7 from 2016). For females, the association of entering reproduction with SFD was analyzed by a Fisher's exact test. All individual female snakes sampled during the vitellogenic/early pregnancy season (March-June) were divided into infected (SFD score $\geq 1$ ) and uninfected groups, and the proportion of individuals that had initiated vitellogenesis or became pregnant (i.e., were vitellogenic or pregnant on recapture later that year) was compared within each group.

To compare visual scoring of the severity of clinical signs of infection (1-3) with the relative amount of O. ophiodiicola DNA on swabs taken from the skin (fungal load), Spearman's rank correlations between PCR cycle threshold values (1-40 cycles, inversely related to the amount of DNA in a sample) and visual SFD score were run. Nonparametric Kruskal-Wallis tests followed by Dunn's correction for multiple pairwise comparisons were used to determine whether the categories of infection severity that were used in seasonal models reflected differences in fungal load.

\section{Results}

Mean monthly cort levels differed by as much as fivefold over the course of 12 mo (table 1). Snakes with severe clinical signs 
Table 1: Sample size $(n)$ and mean untransformed corticosterone concentrations \pm SEM for each month and in snakes scored at the three levels of fungal severity (fungal category)

\begin{tabular}{lccr}
\hline Month & \multicolumn{3}{c}{$\begin{array}{c}\text { Corticosterone } \\
(\mathrm{ng} / \mathrm{mL})\end{array}$} \\
\hline January & 42 & 166.75 & SEM \\
February & 23 & 136.25 & 18.25 \\
March & 38 & 73.23 & 15.02 \\
April & 52 & 79.47 & 12.75 \\
May & 43 & 47.12 & 13.75 \\
June & 39 & 33.69 & 14.44 \\
July & 36 & 30.25 & 15.02 \\
August & 25 & 28.95 & 18.03 \\
September & 43 & 93.67 & 13.91 \\
October & 61 & 125.62 & 12.05 \\
November & 28 & 108.26 & 17.04 \\
December & 34 & 123.89 & 15.94 \\
Fungal category: & & & \\
$\quad$ None & 268 & 69.33 & 5.75 \\
$\quad$ Moderate & 125 & 92.24 & 8.41 \\
Severe & 58 & 165.18 & 12.35 \\
\hline
\end{tabular}

of infection had baseline cort levels approximately twice as high compared to asymptomatic or moderately symptomatic snakes (table 1$)$. There was a significant effect of month $\left(F_{11,216}=13.32\right.$, $P \leq 0.0001)$ in the model including reproductive status as a fixed factor. The effect of reproductive status was not significant $\left(F_{2,19}=1.60, P \leq 0.23\right)$. In the full model, there was a significant effect of month, infection status, and BCI on ln cort (table 2). There were no significant interaction terms in the model (table 2). Post hoc tests show fall and winter peaks and summer lows in $\ln$ cort after accounting for infection and BCI (fig. 1A). In the analysis of month alone, the effect of month is significant $\left(F_{11,218}=\right.$ $14.25, P \leq 0.0001$ ), and post hoc tests demonstrate that cort was significantly higher from the fall until the early spring months (September-April) compared to summer (fig. 1A). When snakes with no clinical signs of infection are analyzed separately, there is a significant effect of month on $\ln$ cort $\left(F_{11,256}=7.05, P \leq\right.$ 0.0001 ), and post hoc tests reveal a high fall and winter and low summer pattern (fig. $1 B$ ). When only snakes with severe clinical signs are analyzed, the effect of month is significant $\left(F_{11,46}=\right.$ $4.75, P \leq 0.001$ ), and post hoc tests reveal a high fall/winter and low summer pattern (fig. $1 B)$. Both BCI $\left(F_{11,221}=9.69, P<\right.$ $0.001)$ and SFD score $\left(F_{11,223}=11.48, P<0.001\right)$ varied by month. Post hoc tests showed that BCI peaked in August and then fell to a seasonal low in January (fig. $1 B$ ). SFD score peaked significantly in late winter and early spring (January, February, and March) and remained relatively low in the summer and fall months (fig. $1 B$ ). Baseline cort was negatively related to BCI regardless of infection status, and post hoc tests on the full model show that snakes with severe infections had significantly higher cort concentrations compared to moderately and uninfected snakes, which were not significantly different from each other (fig. $1 D$ ).

There were significant negative correlations between mean monthly SFD score and BCI and between SFD score and air temperature measured in the previous month (fig. $2 C, 2 D$ ). Disease scores were positively correlated with mean monthly cort measured in the previous month (fig. $2 A$ ). There was a negative trend in the relationship between foraging success (proportion with bolus) and SFD; however, this trend was not significant (fig. 2B). Environmental and physiological variables in the analysis also demonstrated high levels of correlation (table 3).

There was a significant association between SFD infection and the proportion of females that had initiated vitellogenesis (Fisher's exact test, $P=0.03$ ). Fifty-four percent (28 of 52) of asymptomatic females definitely entered reproductive bouts in the spring compared to only $27 \%$ (7 of 26 ) of symptomatic females. Visual assessment of the severity of clinical signs of SFD (SFD score) correlated negatively with PCR cycle threshold (fig. 3).

\section{Discussion}

Our results support the broad hypothesis that SFD is associated with increased HPA activity and allostatic load and are consistent with the predictions of the cort-fitness hypothesis. The seasonal elevation in the severity of clinical signs of SFD was associated with seasonal elevation in cort levels and seasonal decline in BCI. Additionally, severely symptomatic individuals had higher cort levels compared to moderately symptomatic and asymptomatic individuals, and severely symptomatic snakes were in low body condition compared to snakes with less severe clinical signs (McCoy et al. 2017). These results demonstrate that energy is limited and cort is elevated both during the time of year where disease severity is highest in the population and in individual snakes with severe clinical signs of infection and high fungal loads. During fall and winter months, elevated cort, coupled with limited energy avail-

Table 2: Degrees of freedom (df), $F$ statistics, and $P$ values for each effect included in the full model

\begin{tabular}{lcccc}
\hline Effect & df numerator & df denominator & $F$ & $P$ \\
\hline Month & 11 & 168 & 6.96 & $<.001$ \\
Fungal category & 2 & 69 & 5.34 & .007 \\
BCI & 1 & 168 & 6.26 & .01 \\
Month $\times$ fungal category & 22 & 168 & 1.23 & .23 \\
Month $\times$ BCI & 11 & 168 & .9 & .55 \\
Fungal category $\times$ BCI & 2 & 168 & .07 & .94 \\
\hline
\end{tabular}

Note. Significant model effects are shown in bold. BCI = body condition index. 
A.

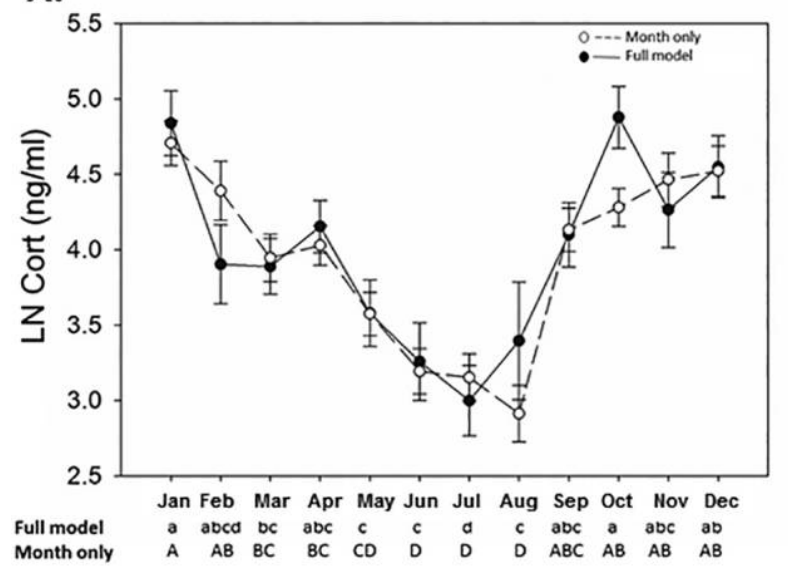

C.

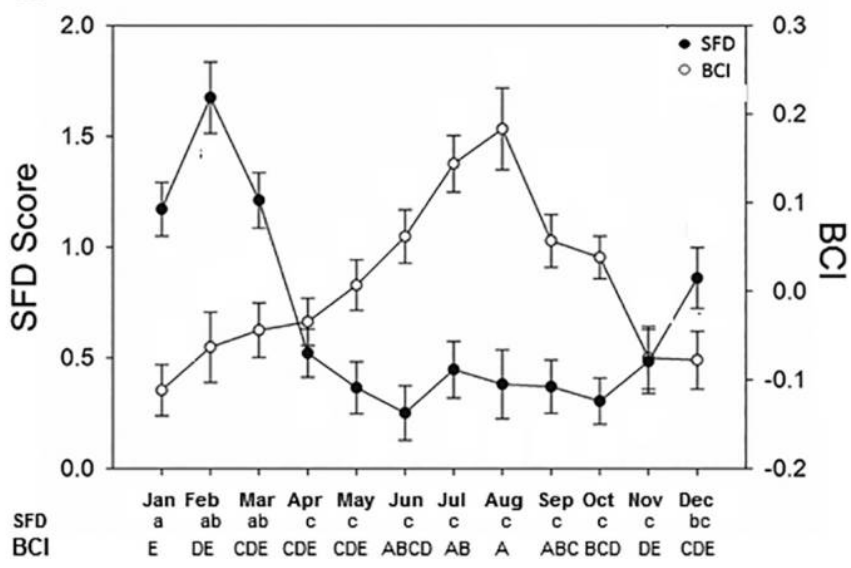

B.

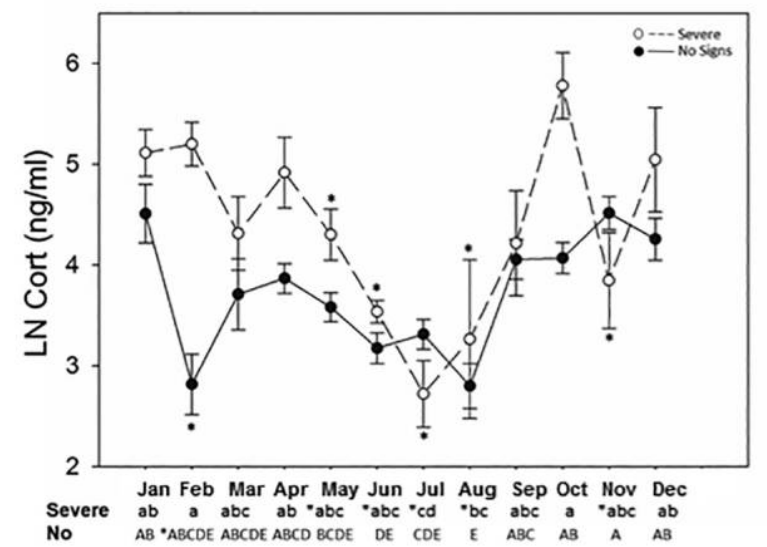

D.

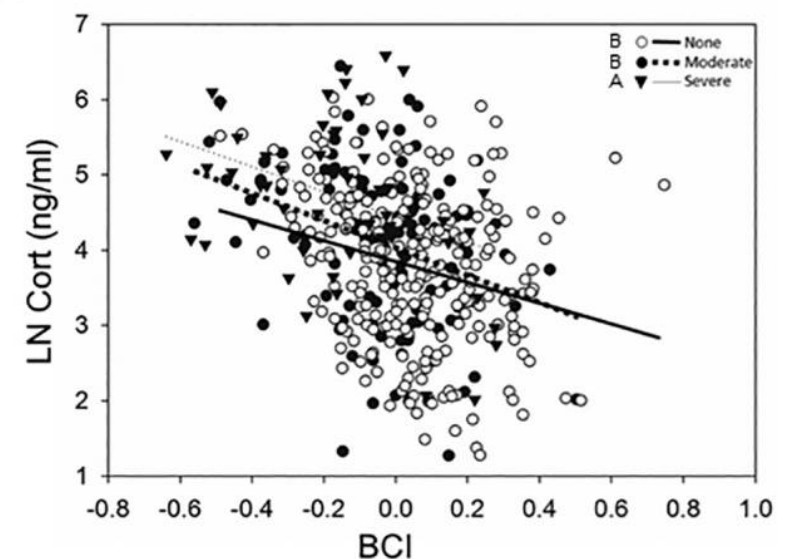

Figure 1. A, Least square mean ln-transformed corticosterone (LN cort) for each month calculated from the full mixed model and least square mean LN cort calculated from a repeated-measures analysis of the effect of month only. $B$, Mean LN cort by month for snakes with no clinical signs of snake fungal disease (SFD) and for snakes with severe signs of SFD. An asterisk indicates a sample size of 3 or fewer. $C$, Mean body condition index (BCI) and SFD score for each month. Results of post hoc pairwise Tukey tests are indicated below each month in $A, B$, and $C$. Months that do not share a letter are significantly different. Error bars represent the standard error of the mean. $D$, Linear relationships between BCI and LN cort within the three levels of SFD severity. Results of post hoc Tukey tests conducted on the full model are shown beside the key.

ability and declining body condition, may synergize to force individuals into allostatic overload (Goymann and Wingfield 2004), resulting in reduced fitness, increased susceptibility to severe infections by Ophidiomyces ophiodiicola, and potentially mortality.

Our results are descriptive and preclude identification of the direction of causality driving the relationship between cort and the severity of clinical signs of SFD. However, seasonal patterns in cort (high fall and winter, low summer) were not significantly different among uninfected, moderately infected, and severely infected snakes, suggesting that cort rises in the fall and remains elevated through winter regardless of disease state. As most studies of HPA function in field-active snakes have focused on hibernating species, our study is the first, to our knowledge, to measure cort levels in a field-active snake population over the course of all $12 \mathrm{mo}$. In most studies of hibernating pit vipers, seasonal patterns in cort have not been observed in nonreproductive surface-active individuals, and cort is not correlated with individual energetic status (Taylor et al. 2004; Lind et al. 2010; Lind and Beaupre 2014, 2015). Although cort increases associated with pregnancy have been doc- umented in many viperids (Taylor et al. 2004; Smith et al. 2012; Loriux et al. 2016), we observed no effect of reproductive status on cort levels. Previous studies on male garter snakes Thamnophis sirtalis documented a summer decline in circulating cort levels, with elevated levels in the months before and after hibernation, a pattern similar to our study (Moore et al. 2000, 2001). In pigmy rattlesnakes, cort remained elevated above summer levels for $6 \mathrm{mo}$ and began to decline in the spring. $\mathrm{BCI}$ began to increase and the severity of clinical signs of SFD began to decrease in the spring as well.

Both the cause and the consequence of elevated GCs in the fall and winter months require experimental investigation. Foraging success, BCI, and air temperature all declined beginning in the fall and continued to decline through winter, and BCI and air temperature were negatively correlated with cort levels and SFD clinical sign severity. Experimental food restriction leads to elevated GC levels in phylogenetically diverse vertebrates (e.g., Stewart et al. 1988; Kitaysky et al. 2001), including some snakes (Webb et al. 2017), and descriptive studies in field-active snakes have demon- 
A.

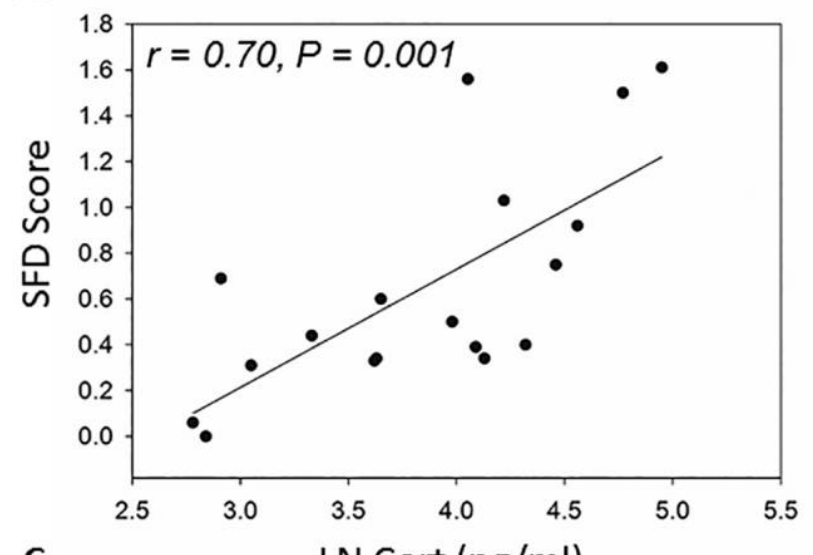

C.

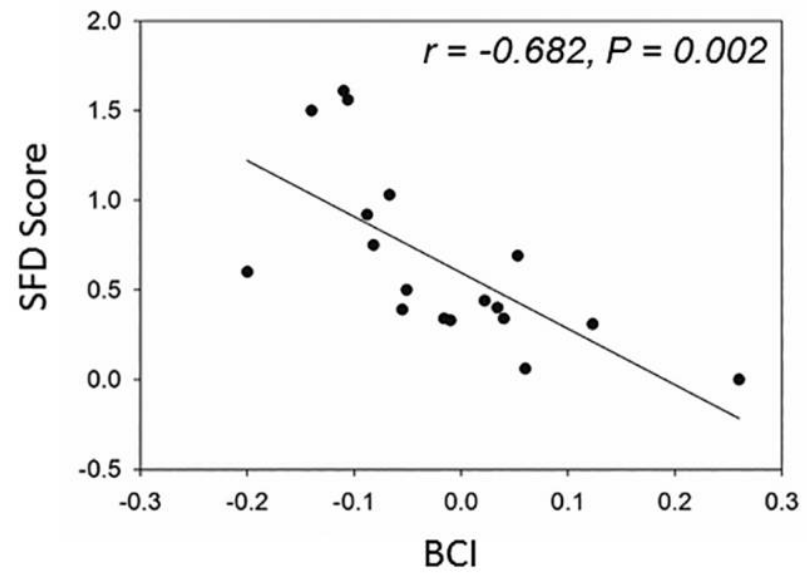

B.

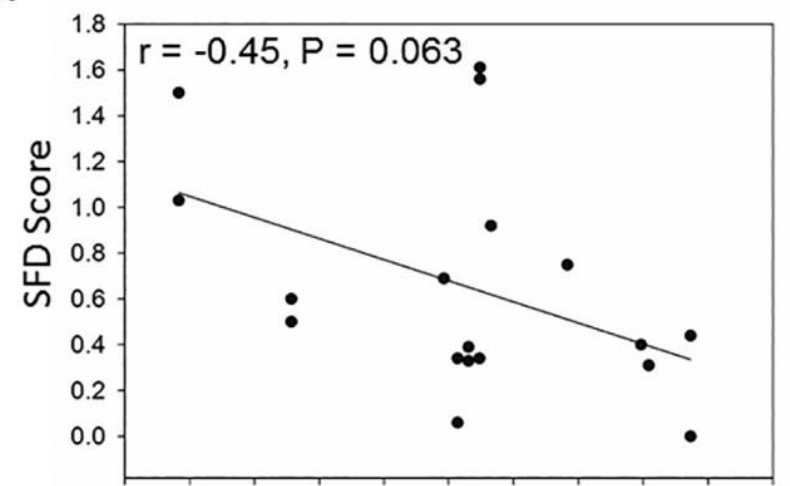

$\begin{array}{lllllllllll}0.00 & 0.02 & 0.04 & 0.06 & 0.08 & 0.10 & 0.12 & 0.14 & 0.16 & 0.18 & 0.20\end{array}$

D.
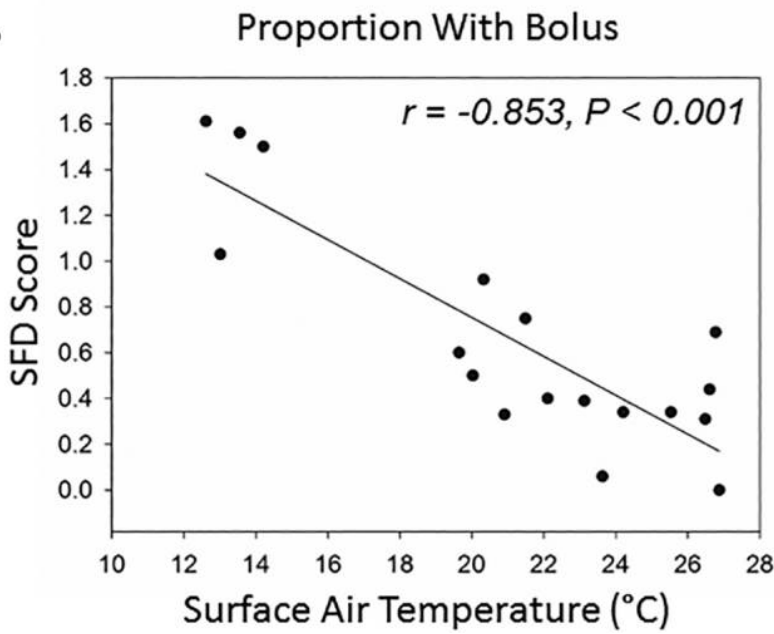

Figure 2. Linear relationships between environmental ( $B$, proportion of captures with a food bolus; $D$, surface air temperature) and physiological $(A, \ln$ corticosterone [LN cort] levels; $C$, body condition) variables calculated in the precedent month and the mean monthly snake fungal disease (SFD) score in the population. Results of Pearson correlations are given at the top of each graph. All significant correlations $(\alpha=0.005)$ are in italics.

strated negative relationships between energetic status and cort levels (Moore et al. 2000, 2001). Snakes experimentally infected with O. ophiodiicola may develop anorexia, which could further raise cort levels and exacerbate the disease process (Lorch et al. 2015). We propose the hypothesis (visualized in fig. 4) that annual patterns in environmental stressors (e.g., temperature) and foraging success may drive annual patterns in baseline cort and that increased allostatic load, coupled with limited foraging success, forces trade-offs among life-history functions and resource allo- cation strategies that can increase susceptibility to SFD. For example, decreased resource availability may reduce the amount of time or energy allocated to preventing or fighting infection. The HPA responds to SFD by further increasing GC production, thus adding to the load and exacerbating trade-offs, which may result in the sort of positive feedback loop of declining condition and increased infection severity described by Beldomenico and Begon (2010) and documented in vertebrate populations afflicted with parasitic diseases (e.g., Eberhartdt et al. 2013). That infection by $O$.

Table 3: Correlation matrix for three physiological and two environmental variables averaged in each month of the study

\begin{tabular}{lccccr}
\hline & $F$ score & BCI & Temperature & Forage & Cort \\
\hline F score & 1 & -.6817 & -.8529 & -.447 & .7033 \\
BCI & $\ldots$ & 1 & .7201 & $\mathbf{. 6 4 5 9}$ & -.6932 \\
Temperature & $\ldots$ & $\ldots$ & 1 & .6306 & -.7132 \\
Forage & $\ldots$ & $\ldots$ & $\ldots$ & 1 & -.3617 \\
Cort & $\ldots$ & $\ldots$ & $\ldots$ & $\ldots$ & 1 \\
\hline
\end{tabular}

Note. Physiological variables: $F$ score $=$ SFD severity score, $\mathrm{BCI}=$ body condition index, cort $=\ln$-transformed corticosterone. Environmental variables: temperature $=$ mean surface air temperature, forage $=$ proportion of captures with a food bolus. Mean $F$ scores used in correlations are those calculated in the month following all other variables. Significant correlations are shown in bold $(\alpha=0.005)$. 


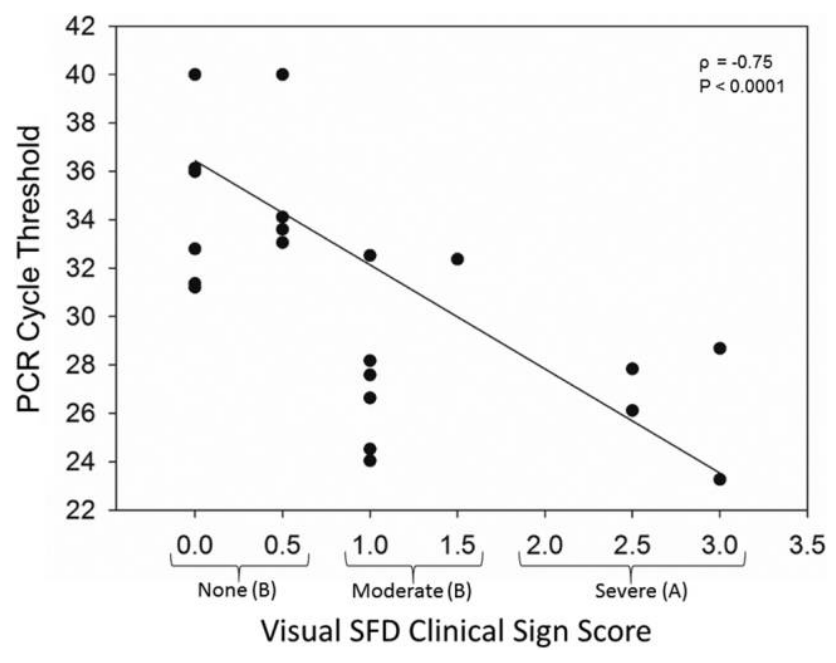

Figure 3. Scatterplots with linear regression lines and the result of Spearman correlations between visual snake fungal disease (SFD) score and realtime polymerase chain reaction (PCR) cycle threshold (Ct). Ct is negatively correlated with the abundance of fungal DNA on swabs (i.e., low Ct values indicate high fungal loads). Fungal categories used in statistical models are indicated below the $X$-axis. Results of post hoc Dunn's tests are shown next to each category of clinical sign severity. Categories that do not share a letter are significantly different.

ophiodiicola may result in behavioral or physiological responses (i.e., increased molting and anorexia) that further add to the allostatic load and compromise host energy budget has been proposed (Lorch et al. 2015) but was not previously corroborated by physiological data.

The potential for positive feedback loops associated with seasonal shifts in the biophysical or resource environment and allostatic load to drive dynamics in snake populations afflicted with SFD requires further investigation. Other fungal diseases such as white nose syndrome (WNS) in bats and chytridiomycosis in amphibians have emerged recently and have led to widespread population declines and extinctions in host taxa (Pounds et al. 2006; Skerratt et al. 2007; Frick et al. 2010). The HPA and energetic response to infection in both cases demonstrate some similarities to the relationships observed in pigmy rattlesnakes with SFD. WNS afflicts hibernating bats during winter. GCs are elevated in bats in preparation for and during hibernation (Reeder et al. 2004), and elevated GCs may correlate with suppression of the immune system during hibernation (Bouma et al. 2010). Estimates of fat utilization in bats with WNS are twofold higher compared to uninfected bats, and increased utilization of stored energy begins before the onset of clinical signs of infection (Verant et al. 2014). High allostatic loads resultant from infection decrease the probability of individuals surviving "a tight winter energetic bottleneck" (Willis and Wilcox 2014, p. 70), where the primary cause of mortality is likely starvation before the spring increase in temperature and food availability. Pigmy rattlesnakes may face a similar, though less extreme, energetic bottleneck as foraging success and thermoregulatory opportunity in the population remain low through winter and the positive feedback loop of disease and declining condition continues until resources return and temperatures rise in the spring. In the case of chytridiomycosis in frogs, the HPA axis is upregulated during infection (Gabor et al. 2013). Although exogenous administration of GCs does not alter infection outcomes in some cases (Searle et al. 2014), GCs have been shown to suppress branches of the amphibian innate immune system, including expression of skin antimicrobial peptides (Simmaco et al. 1997), a first line of defense against chytrid infection (Rollins-Smith et al. 2002a, 2002b; Harris et al. 2006; Lam et al. 2010). Exogenous GCs also decrease cutaneous wound healing (Thomas and Woodly 2015). The commonalities between our results and results of the intensive study of WNS and chytridiomycosis suggest that the interplay among host HPA activity, immunocompetence, and energetics may determine infection outcomes. Seasonal shifts in any of these components can result in seasonal patterns of infection severity, particularly during seasons where HPA activity its high and energy is limited.

Other than its direct link to mortality in some species (Allender et al. 2011; Clark et al. 2011), the specific effects of SFD on population dynamics are unknown. Our results are consistent with the predictions of the cort-fitness hypothesis. The severity of clinical signs was associated with elevated cort (in general) and reduced short-term fitness (in females). The analysis of the proportion of symptomatic versus asymptomatic females that initi-

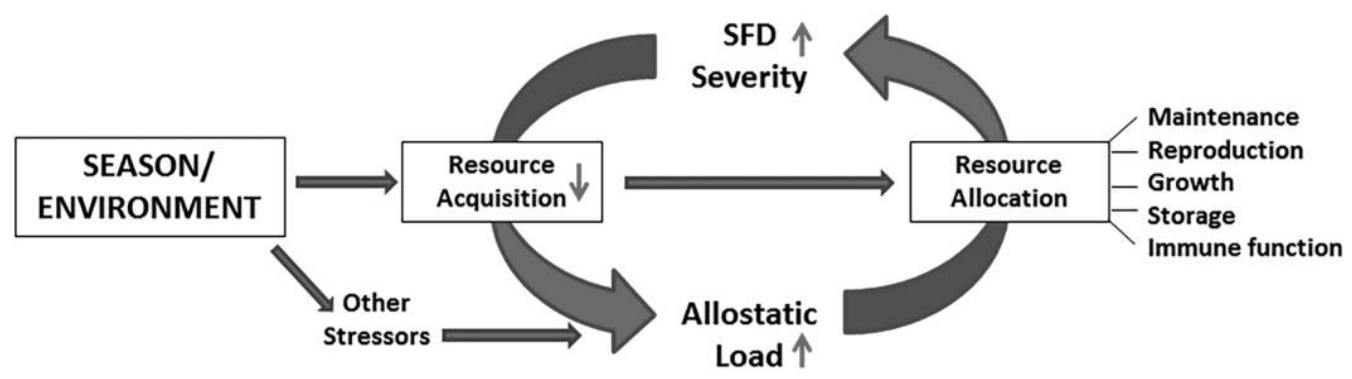

Figure 4. Hypothesized positive feedback loop (vicious circle) diagraming how seasonal stressors or shifts in food resources may fuel a cycle where increased allostatic load and low seasonal resource abundance lead to allocation outcomes that may increase the susceptibility to snake fungal disease (SFD) and/or deplete stored resources. SFD infection then adds to the allostatic load and exacerbates trade-offs among life-history functions, leading to further depletion of stored energy and decreased capacity to fight the infection. A color version of this figure is available online. 
ated vitellogenesis in the spring suggests that females exhibiting clinical signs of SFD were about half as likely to enter reproductive bouts. Females that did enter spring reproductive bouts (i.e., were vitellogenic or pregnant) did not exhibit elevated cort levels, exhibited fewer clinical signs of SFD, and, in another study, had an equally robust innate immune response compared to the general population (McCoy et al. 2017). In species in which some individuals do not reproduce each year, including pit vipers (Bull and Shine 1979), such a result suggests that either (1) infected, energetically compromised snakes with elevated GCs resultant from infection and/or poor condition may forgo reproductive opportunities or (2) females in poor condition in the fall, and particularly females that reproduced in the previous year, are energetically compromised and more vulnerable to SFD. Additionally, in a species such as $S$. miliarius, which likely relies largely on stored energy for reproduction, individual BCI may be implicitly linked to annual reproductive success (Naulleau and Bonnet 1996), and the observed relationships among SFD, cort, and BCI are consistent with the cort-fitness hypothesis.

The effects of abiotic factors such as temperature on both host and pathogen (independent of the HPA) cannot be ignored in the explanation of observed seasonal patterns of infection severity. Ophidiomyces ophiodiicola grows best at $25^{\circ} \mathrm{C}$, and growth inhibition occurs at $35^{\circ} \mathrm{C}$ (Allender et al. 2015). Basking pigmy rattlesnakes can achieve cloacal temperatures approaching and even exceeding $35^{\circ} \mathrm{C}$ in the field, but body temperatures exceeding $35^{\circ} \mathrm{C}$ are observed very rarely, especially in the winter months (May et al. 1996). Individuals may be able to combat the fungus by inducing fever through altered thermoregulatory behavior (Kluger et al. 1975). Indeed, snakes with SFD are believed to bask to attain body temperatures conducive to fighting infection (Lorch et al. 2015). However, this ability may be limited in winter, and, as the metabolic rates of ectotherms are temperature dependent (Gillooly et al. 2001), such behaviors may come at a high energetic cost and contribute to the allostatic load. Additionally, effects of temperature on immune function have been documented in a variety of ectothermic vertebrates (Le Morvan et al. 1998; Merchant et al. 2003, 2005; Raffel et al. 2006), and seasonal shifts in thermoregulatory opportunity may impact immunocompetence through direct thermal effects.

As is the case with many fungal pathogens (DeShaw and Pirofski 1995), prevalence of O. ophiodiicola on the host (i.e., the detectable presence of the fungus) is higher than the prevalence of clinical signs indicative of disease. Of the 29 snakes sampled in the fall of 2016, 19 individuals (65\%) tested positive for O. ophiodiicola DNA despite only 12 individuals (41\%) presenting with one or more grossly visible lesions consistent with SFD. Snakes that were asymptomatic yielded real-time PCR cycle threshold $(\mathrm{Ct})$ values that were higher compared to snakes that had visible lesions (fig. 3). Higher Ct values typically indicate a lower abundance of target organism DNA, and the snakes without clinical signs may have simply been carrying O. ophiodiicola on their skin in the absence of infection. Nonetheless, PCR results indicate that the prevalence of $O$. ophiodiicola is high in the fall months but that some individuals were either carriers of $O$. ophiodiicola or were in early stages of infection and may have gone on to show more severe clinical signs in winter. Prevalence of $O$. ophiodiicola was much higher compared to reports in a closely related rattlesnake, Sistrurus catenatus (Allender et al. 2013); however, differences in methodology or the season in which samples were taken cannot be ruled out as potential sources of such differences. Further research is required to determine whether the prevalence of $O$. ophiodiicola and fungal loads follow a seasonal pattern similar to the prevalence of disease documented in pigmy rattlesnakes here and in McCoy et al. (2017).

In conclusion, our results highlight several main points and generate hypotheses that may explain seasonal infection patterns observed in wild snakes. First, the detection of O. ophiodiicola DNA on the skin was high in snakes sampled in the fall, a season where clinical severity was not at its seasonal peak. Declines in body condition, foraging success, a measure of innate immune function (McCoy et al. 2017), and temperature coincided with increased baseline cort levels in the fall and preceded the seasonal rise in infection severity. Additionally, snakes with severe clinical signs of infection exhibited physiological stress as indicated by elevated cort levels, and cort levels were higher in the infected individuals that were the most energetically compromised. Taken together, our results are consistent with the hypothesis that seasonal fluctuation in the environment (e.g., food availability and/or temperature) initiates a positive feedback loop of negative energy balance (declining BCI), elevated cort, and infection in the fall, which drives the late-winter peak in SFD severity. Snakes that enter this cycle with greater energy stores or are successful at foraging in the winter months may be less likely to enter allostatic overload or succumb to SFD. Our results are descriptive and do not directly estimate the energetic consequences of SFD infection or other components of stress and allostatic load independent of plasma cort. Future field and laboratory experiments should be employed to (1) establish causal links among environmental variables, HPA function, and infection by O. ophiodiicola and (2) quantify the total energetic costs of coping with SFD.

\section{Literature Cited}

Allender M.C., M.J. Dreslik, S.J. Wylie, C. Phillips, D.B. Wylie, C. Maddox, M.A. Delaney, and M.J. Kinsel. 2011. Chrysosporium sp. infection in eastern massasauga rattlesnakes. Emerg Infect Dis 17:2383-2385.

Allender M.C., M.J. Dreslik, D.B. Wylie, S.J. Wylie, J.W. Scott, and C.A. Phillips. 2013. Ongoing health assessment and prevalence of Chrysosporium in the eastern massasauga (Sistrurus catenatus catenatus). Copeia 2013:97-102.

Allender M.C., D.B. Raudabaugh, F.H. Gleason, and A.N. Miller. 2015. The natural history, ecology, and epidemiology of Ophidiomyces ophiodiicola and its potential impact on free-ranging snake populations. Fungal Ecol 17:187-196.

Beldomenico P.M. and M. Begon. 2010. Disease spread, susceptibility and infection intensity: vicious circles? Trends Ecol Evol 25:21-27.

Berger S., L.B. Martin, M. Wikelski, L.M. Romero, E.K. Kalko, M.N. Vitousek, and T. Rödl. 2005. Corticosterone suppresses 
immune activity in territorial Galapagos marine iguanas during reproduction. Horm Behav 47:419-429.

Bohuski E., J.M. Lorch, K.M. Griffin, and D.S. Blehert. 2015. TaqMan real-time polymerase chain reaction for detection of Ophidiomyces ophiodiicola, the fungus associated with snake fungal disease. BMC Vet Res 11:95.

Bonier F., P.R. Martin, I.T. Moore, and J.C. Wingfield. 2009a. Do baseline glucocorticoids predict fitness? Trends Ecol Evol 24: 634-642.

Bonier F., I.T. Moore, P.R. Martin, and R.J. Robertson. $2009 b$. The relationship between fitness and baseline glucocorticoids in a passerine bird. Gen Comp Endocrinol 163:208-213.

Bouma H.R., H.V. Carey, and F.G. Kroese. 2010. Hibernation: the immune system at rest? LLeukoc Biol 88:619-624.

Bull J.J. and R. Shine. 1979. Iteroparous animals that skip opportunities for reproduction. Am Nat 114:296-303.

Burnham K.P. and D.R. Anderson. 2002. Model selection and multi-model inference: a practical information-theoretic approach. Springer, New York.

Buttemer W.A., L.B. Astheimer, and J.C. Wingfield. 1991. The effect of corticosterone on standard metabolic rates of small passerine birds. L Comp Physiol B 161:427-431.

Cheatwood J.L., E.R. Jacobson, P.G. May, T.M. Farrell, B.L. Homer, D.A. Samuelson, and J.W. Kimbrough. 2003. An outbreak of fungal dermatitis and stomatitis in a free-ranging population of pigmy rattlesnakes, Sistrurus miliarius, in Florida. Wildl Dis 39:329-337.

Clark R.W., M.N. Marchand, B.J. Clifford, R. Stechert, and S. Stephens. 2011. Decline of an isolated timber rattlesnake (Crotalus horridus) population: interactions between climate change, disease, and loss of genetic diversity. Biol Conserv 144: 886-891.

DeShaw M. and L.A. Pirofski. 1995. Antibodies to the Cryptococcus neoformans capsular glucuronoxylomannan are ubiquitous in serum from HIV + and HIV-individuals. Clin Exp Immunol 99:425-432.

Dolinski A.C., M.C. Allender, V. Hsiao, and C.M. Maddox. 2014. Systemic Ophidiomyces ophiodiicola infection in a freeranging plains garter snake (Thamnophis radix). L Herpetol Med Surg 24:7-10.

Eberhardt A.T., S.A. Costa, M.R. Marini, A. Racca, C.J. Baldi, M.R. Robles, P.G. Moreno, and P.M. Beldomenico. 2013. Parasitism and physiological trade-offs in stressed capybaras. PLoS ONE 8: e70382.

Frick W.F., J.F. Pollock, A.C. Hicks, K.E. Langwig, D.S. Reynolds, G.G. Turner, C.M. Butchkoski, and T.H. Kunz. 2010. An emerging disease causes regional population collapse of a common North American bat species. Science 329:679682.

Gabor C.R., M.C. Fisher, and J. Bosch. 2013. A non-invasive stress assay shows that tadpole populations infected with Batrachochytrium dendrobatidis have elevated corticosterone levels. PLOS ONE 8:e56054.

Gillooly J.F., J.H. Brown, G.B. West, V.M. Savage, and E.L. Charnov. 2001. Effects of size and temperature on metabolic rate. Science 293:2248-2251.
Goymann W. and J.C. Wingfield. 2004. Allostatic load, social status and stress hormones: the costs of social status matter. Anim Behav 67:591-602.

Harris R.N., T.Y. James, A. Lauer, M.A. Simon, and A. Patel. 2006. Amphibian pathogen Batrachochytrium dendrobatidis is inhibited by the cutaneous bacteria of amphibian species. EcoHealth 3:53-56.

Hyatt A.D., D.G. Boyle, V. Olsen, D.B. Boyle, L. Berger, D. Obendorf, A. Dalton, et al. 2007. Diagnostic assays and sampling protocols for the detection of Batrachochytrium dendrobatidis. Dis Aquat Org 73:175-192.

Jemison S.C., L.A. Bishop, P.G. May, and T.M. Farrell. 2005. The impact of PIT-tags on the growth and movement of the rattlesnake, Sistrurus miliarius. LHerpetol 29:129132.

Kitaysky A.S., E.V. Kitaiskaia, J.C. Wingfield, and J.F. Piatt. 2001. Dietary restriction causes chronic elevation of corticosterone and enhances stress response in red-legged kittiwake chicks. L Comp Physiol B 171:701-709.

Kluger M.J., D.H. Ringler, and M.R. Anver. 1975. Fever and survival. Science 188:166-168.

Korte S.M., J.M. Koolhaas, J.C. Wingfield, and B.S. McEwen. 2005. The Darwinian concept of stress: benefits of allostasis and costs of allostatic load and the trade-offs in health and disease. Neurosci Biobehav Rev 29:3-38.

Lam B.A., J.B. Walke, V.T. Vredenburg, and R.N. Harris. 2010. Proportion of individuals with anti-Batrachochytrium dendrobatidis skin bacteria is associated with population persistence in the frog Rana muscosa. Biol Conserv 143:529-531.

Latney L.V. and J. Wellehan. 2013. Selected emerging infectious diseases of Squamata. Vet Clin N Am Exot Anim Pract 16:319338.

Le Morvan C., D. Troutaud, and P. Deschaux. 1998. Differential effects of temperature on specific and nonspecific immune defenses in fish. LExp Biol 201:165-168.

Lind C.M. and S.J. Beaupre. 2014. Natural variation in steroid hormone profiles of male timber rattlesnakes, Crotalus horridus, in northwest Arkansas. Gen Comp Endocrinol 206:7279 .

. 2015. Male snakes allocate time and energy according to individual energetic status: body condition, steroid hormones, and reproductive behavior in timber rattlesnakes, Crotalus horridus. Physiol Biochem Zool 88:624-633.

Lind C.M., J.F. Husak, C. Eikenaar, I.T. Moore, and E.N. Taylor. 2010. The relationship between plasma steroid hormone concentrations and the reproductive cycle in the northern Pacific rattlesnake, Crotalus oreganus. Gen Comp Endocrinol 166: 590-599.

Lorch J.M., S. Knowles, J.S. Lankton, K. Michell, J.L. Edwards, J.M. Kapfer, R.A. Staffen, et al. 2016. Snake fungal disease: an emerging threat to wild snakes. Philos Trans R Soc B 371. doi: 10.1098/rstb.2015.0457.

Lorch J.M., J. Lankton, K. Werner, E.A. Falendysz, K. McCurley, and D.S. Blehert. 2015. Experimental infection of snakes with Ophidiomyces ophiodiicola causes pathological changes that typify snake fungal disease. mBio 6:e01534-15. 
Lorioux S., F. Angelier, and O. Lourdais. 2016. Are glucocorticoids good indicators of pregnancy constraints in a capital breeder? Gen Comp Endocrinol 232:125-133.

Marin M.T., F.C. Cruz, and C.S. Planeta. 2007. Chronic restraint or variable stresses differently affect the behavior, corticosterone secretion and body weight in rats. Physiol Behav 90:29-35

Martin L.B. 2009. Stress and immunity in wild vertebrates: timing is everything. Gen Comp Endocrinol 163:70-76.

May P.G. and T.M. Farrell. 2012. Patterns of growth in a central Florida population of pigmy rattlesnakes (Sistrurus miliarius). Herpetol Monogr 26:58-79.

May P.G., T.M. Farrell, S.T. Heulett, M.A. Pilgrim, L.A. Bishop, D.J. Spence, A.M. Rabatsky, M.G. Campbell, A.D. Aycrigg, and W.E. Richardson. 1996. Seasonal abundance and activity of a rattlesnake (Sistrurus miliarius barbouri) in central Florida. Copeia 1996:389-401.

McBride M.P., K.B. Wojick, T.A. Georoff, J. Kimbro, M.M. Garner, X. Wang, A.L. Childress, and J.F. Wellehan. 2015. Ophidiomyces ophiodiicola dermatitis in eight free-ranging timber rattlesnakes (Crotalus horridus) from Massachusetts. JZoo Wildl Med 46:86-94.

McCoy C.M., C.M. Lind, and T.M. Farrell. 2017. Physiological and environmental correlates of the severity of clinical signs of snake fungal disease in free ranging pigmy rattlesnakes, Sistrurus miliarius. Conserv Physiol 5. doi:10.1093/conphys/cow077.

McEwen B.S. and J.C. Wingfield. 2003. The concept of allostasis in biology and biomedicine. Horm Behav 43:2-15.

Merchant M., M. Pallansch, R.L. Paulman, J.B. Wells, A. Nalca, and R. Ptak. 2005. Antiviral activity of serum from the American alligator (Alligator mississippiensis). Antivir Res 66:35-38.

Merchant M., C. Roche, R.M. Elsey, and J. Prudhomme. 2003. Antibacterial properties of serum from the American alligator (Alligator mississippiensis). Comp Biochem Physiol B 136:505-513.

Moore F.L. and R.T. Zoeller. 1985. Stress-induced inhibition of reproduction: evidence of suppressed secretion of LH-RH in an amphibian. Gen Comp Endocrinol 60:252-258.

Moore I.T. and T.S. Jessop. 2003. Stress, reproduction, and adrenocortical modulation in amphibians and reptiles. Horm Behav 43:39-47.

Moore I.T., J.P. Lerner, D.T. Lerner, and R.T. Mason. 2000. Relationships between annual cycles of testosterone, corticosterone, and body condition in male red-spotted garter snakes, Thamnophis sirtalis concinnus. Physiol Biochem Zool 73:307-312.

Moore I.T. and R.T. Mason. 2001. Behavioral and hormonal responses to corticosterone in the male red-sided garter snake, Thamnophis sirtalis parietalis. Physiol Behav 72:669-674.

Morici L.A., R.M. Elsey, and V.A. Lance. 1997. Effects of long-term corticosterone implants on growth and immune function in juvenile alligators, Alligator mississippiensis. L Exp Zool 279: 156-162.

Naulleau G. and X. Bonnet. 1996. Body condition threshold for breeding in a viviparous snake. Oecologia 107:301-306.

Pounds J.A., M.R. Bustamante, L.A. Coloma, J.A. Consuegra, M.P. Fogden, P.N. Foster, E. La Marca, et al. 2006. Widespread amphibian extinctions from epidemic disease driven by global warming. Nature 439:161-167.
Rafffel T.R., J.R. Rohr, J.M. Kiesecker, and P.J. Hudson. 2006. Negative effects of changing temperature on amphibian immunity under field conditions. Funct Ecol 20:819-828.

Reeder D.M., N.S. Kosteczko, T.H. Kunz, and E.D. Widmaier. 2004. Changes in baseline and stress-induced glucocorticoid levels during the active period in free-ranging male and female little brown myotis, Myotis lucifugus (Chiroptera: Vespertilionidae). Gen Comp Endocrinol 136:260-269.

Reeder D.M. and K.M. Kramer. 2005. Stress in free-ranging mammals: integrating physiology, ecology, and natural history. I Mammal 86:225-235.

Rollins-Smith L.A., C. Carey, J. Longcore, J.K. Doersam, A. Boutte, J.E. Bruzgal, and J.M. Conlon. 2002a. Activity of antimicrobial skin peptides from ranid frogs against Batrachochytrium dendrobatidis, the chytrid fungus associated with global amphibian declines. Dev Comp Immunol 26:471-479.

Rollins-Smith L.A., J.K. Doersam, J.E. Longcore, S.K. Taylor, J.C. Shamblin, C. Carey, and M.A. Zasloff. 2002b. Antimicrobial peptide defenses against pathogens associated with global amphibian declines. Dev Comp Immunol 26:63-72.

Romero L.M. 2002. Seasonal changes in plasma glucocorticoid concentrations in free-living vertebrates. Gen Comp Endocrinol 128:1-24.

2004. Physiological stress in ecology: lessons from biomedical research. Trends Ecol Evol 19:249-255.

Sapolsky R.M., L.M. Romero, and A.U. Munck. 2000. How do glucocorticoids influence stress responses? integrating permissive, suppressive, stimulatory, and preparative actions. Endocr Rev 21:55-89.

Schuett G.W., E.N. Taylor, E.A. van Kirk, and W.J. Murdoch. 2004. Handling stress and plasma corticosterone levels in captive male western diamond-backed rattlesnakes (Crotalus atrox). Herpetol Rev 35:229-232.

Searle C.L., L.K. Belden, P. Du, and A.R. Blaustein. 2014. Stress and chytridiomycosis: exogenous exposure to corticosterone does not alter amphibian susceptibility to a fungal pathogen. I Exp Zool A 321:243-253.

Simmaco M., A. Boman, M.L. Mangoni, G. Mignogna, R. Miele, D. Barra, and H.G. Boman. 1997. Effect of glucocorticoids on the synthesis of antimicrobial peptides in amphibian skin. FEBS Lett 416:273-275.

Skerratt L.F., L. Berger, R. Speare, S. Cashins, K.R. McDonald, A.D. Phillott, H.B. Hines, and N. Kenyon. 2007. Spread of chytridiomycosis has caused the rapid global decline and extinction of frogs. EcoHealth 4:125-134.

Smith C.F., G.W. Schuett, and S.K. Hoss. 2012. Reproduction in female copperhead snakes (Agkistrodon contortrix): plasma steroid profiles during gestation and post-birth periods. Zool Sci 29:273-279.

Stewart J., M.J. Meany, D. Aitken, L. Jensen, and N. Kalant. 1988. The effects of acute and life-long food restriction on basal and stress-induced serum corticosterone levels in young and aged rats. Endocrinology 123:1934-1941.

Sutherland W., R. Aveling, T. Brooks, M. Clout, L. Dicks, L. Fellman, E. Fleishman, et al. 2014. A horizon scan of global conservation issues for 2014. Trends Ecol Evol 29:15-22. 
Taylor E.N. and D.F. DeNardo. 2005. Reproductive ecology of western diamond-backed rattlesnakes (Crotalus atrox) in the Sonoran Desert. Copeia 2005:152-158.

Taylor E.N., D.F. DeNardo, and D.H. Jennings. 2004. Seasonal steroid hormone levels and their relation to reproduction in the western diamond-backed rattlesnake, Crotalus atrox (Serpentes: Viperidae). Gen Comp Endocrinol 136:328337.

Thomas J.R. and S.K. Woodley. 2015. Treatment with corticosterone delays cutaneous wound healing in male and female salamanders. Gen Comp Endocrinol 216:33-38.

Verant M.L., C.U. Meteyer, J.R. Speakman, P.M. Cryan, J.M. Lorch, and D.S. Blehert. 2014. White-nose syndrome initiates a cascade of physiologic disturbances in the hibernating bat host BMC Physiol 14:10.

Webb A.N., L.D. Chick, V.A. Cobb, and M. Klukowski. 2017. Effects of moderate food deprivation on plasma corticosterone and blood metabolites in common watersnakes (Nerodia sipedon). L Herpetol 51:134-141.

Willis C.K. and A. Wilcox. 2014. Hormones and hibernation: possible links between hormone systems, winter energy balance and white-nose syndrome in bats. Horm Behav 66:66-73.

Wingfield J.C., D.L. Maney, C.W. Breuner, J.D. Jacobs, S. Lynn, M. Ramenofsky, and R.D. Richardson. 1998. Ecological bases of hormone-behavior interactions: the "emergency life history stage." Am Zool 38:191-206. 